\title{
Católicos, CONTROL IDEOLógico Y CUESTIÓN OBRERA.
}

\author{
El Periódico la Verdad de Rosario (1930-1946)
}

María Pía Martín*

\section{El catolicismo social en Rosario}

La encíclica Rerum Novarum, dada a conocer por León XIII en 1891, venía a encauzar la polémica que, sobre la cuestión social, se había instalado en el seno de la Iglesia Católica, desde la segunda mitad del siglo XIX.(1) En consecuencia, pocos años después, se iniciaban en la Argentina las primeras actividades del denominado catolicismo social, movimiento inspirado en ella. A partir de 1892, el Pbro. Federico Grote comenzó la fundación de Círculos de Obreros que se distribuirían por todo el país, creándose el de Rosario en 1895. Estos Círculos constituyeron entidades mutualistas destinadas a "promover y defender el bienestar material y espiritual de la clase obrera", a fin de contrarrestar "la funesta propaganda del socialismo y de la impiedad...", según rezaba su acta fundacional. (2) Por consiguiente, excediendo el estrecho marco del socorro mutuo, en su interior se desarrollaron actividades de propaganda y adoctrinamiento, se formaron patronatos y, luego, mediante la Liga Democrática Cristiana - LDC-, sindicatos de obreros cristianos. ${ }^{(3)}$

El Círculo de Obreros de Rosario - COR - constituyó la primera obra social católica de envergadura, que logró no sólo perpetuarse en el tiempo sino, también, constituirse en uno de los Círculos de mayor vitalidad, sobre todo en la década de 1920. Durante este período, la institución amplió notablemnente el número de sus socios efectivos, pasando de 4.321, en 1921, a 7.502, en 1929. Por otro lado, en 1930,

\footnotetext{
* CONICET / Universidad Nacional de Rosario.
} 
sus 7.454 socios representaban el $24,3 \%$ de los afiliados a la Federación de Círculos de la República Argentina. ${ }^{(4)} \mathrm{Al}$ comenzar la década de 1940, la cifra rondaría los 8.000 socios. ${ }^{(5)}$

Hasta 1908, el COR reveló una tendencia conservadora que lo comprometía con la acción sindical amarilla y lo hacía simpatizar con ciertas entidades patronales, aun cuando el propio Grote - asesor nacional de los Círculos-, había abandonado esa posición tres años antes. ${ }^{(6)}$ Sin embargo, entre 1907/1908 y 1912 comenzaron a insinuarse cambios que cristalizarían en el período siguiente. La renovación de socios de la institución -conducida por sectores medios de origen inmigrantegracias a la incorporación de generaciones jóvenes, muchas veces hijos de los fundadores; la multiplicación de actividades; el contacto con propagandistas portenoos, vinculados a la LDC y al cooperativismo cristiano, como el Pbro. Gustavo Franceschi y el promotor de Cajas Rurales, Serralunga Langhi, provocaron un replanteo de las prácticas institucionales. Asimismo, contribuyó a ello el estrecho lazo establecido con el Obispo Diocesano, Monseñor Agustín Boneo. (7)

En la segunda década del siglo, se estableció, en la ciudad, la Unión Democrática Cristiana, que se perfilaba, en términos relativos, como la corriente más progresista del catolicismo social argentino. Esta agrupación entendía que el catolicismo debía propiciar cierto cambio social partiendo de la transformación de las pautas vigentes en la economía y de una legislación social adecuada. Y esto sólo podría lograrse mediante la organización de un partido obrero católico, que desarrollara acción política y sindical, complementariamente, para conseguir las reformas que se propugnaban. Con esta lógica, en 1905, llegaron a admitir alianzas coyunturales con los sectores dominantes en el sindicalismo, revelando un pluralismo hasta entonces inédito. ${ }^{(8)}$

A diferencia de lo sucedido en otros lugares, en Rosario, la propuesta de estos demócratas se difundió a través del propio COR y gracias a la protección que les brindó el Obispo Boneo. ${ }^{(9)}$ Pero también comenzó a constituirse, a partir de esta militancia, una élite católica dispuesta a llevar a cabo la labor de recristianización que se proponía el Obispo para la Diócesis. Esto significaba, básicamente, expandir y afirmar la presencia de la Iglesia Católica, sobre todo entre los sectores populares. Para ello se recurrió a conferencias callejeras, círculos de estudios, organizaciones obreras, ${ }^{(10)}$ mutualismo, acción parroquial, instalación de escuelas confesionales. ${ }^{(11)}$

De este modo, a partir de su pertenencia al COR y a la Unión Democrática Cristiana, de sus actividades propagandísticas y de su colaboración con la curia local, un núcleo reducido de hombres logró ascender en la escala social y proyectarse a la esfera pública conformando la cara laica de la Iglesia institucional. Durante la década de 1930, esta élite quedó claramente definida, a la vez que, fiel a los dictados de la Jerarquía, debió reorientar sus iniciativas y su experiencia, impulsando en la Diócesis la organización de la Acción Católica Argentina - ACAfundada en 1931. Por otro lado, bajo el influjo de la nueva encíclica social del Papa 
Pío XI - Quadragesimo Anno- se reforzaron sus ideas reformistas, promoviendo el sindicalismo, el intervencionismo estatal y la distribución económica, a la vez que se acentuaron tendencias corporativistas que ya estaban latentes a comienzos de siglo. ${ }^{(12)}$ Por otro lado, desde 1927, abandonaron cualquier predisposición al pluralismo, profundizando un discurso político autoritario y propugnando una fuerte confesionalidad en todas sus actividades. ${ }^{(13)}$ Esto resulta coherente con el avance de las tendencias integristas, atraídas por las alternativas que parecian ofrecer los fascismos europeos y que, al promediar los años ' 30 , se verían conmocionadas por los sucesos de la Guerra Civil Española. (14)

De esta dirigencia laica promovida por la institución, emergieron funcionarios públicos, diputados, concejales, senadores, en distintos momentos y en ocasión de los gobiernos más diversos. ${ }^{(15)}$ Aparentemente, se seguía un cursus honorum que arrancaba de la militancia en diversas entidades de inspiración socialcristiana, particularmente en sus áreas de formación doctrinal, prensa y propaganda, y del ejercicio de una profesión al servicio de la Iglesia; se pasaba, luego, a ocupar ciertos cargos en el ámbito social y político; y, finalmente, su actividad intelectual solía plasmarse en publicaciones destinadas a propagar, en diversos campos, una ideología afin con la doctrina eclesiástica. ${ }^{(16)}$

Entre 1930 y 1943, los dirigentes más relevantes lograron trascender sus propios periódicos, ${ }^{(17)}$ accediendo a medios de alcance masivo, como la radio, o el diario La Capital, de significativa trayectoria en la ciudad. ${ }^{(18)}$ En todos los casos, ellos actuaban como hombres de la Iglesia, estrechamente ligados al Obispado, y dispuestos a ir donde se los mandara. Asimismo, la élite fue reforzando sus vínculos internos mediante alianzas matrimoniales, a la vez que creó espacios de sociabilidad compartidos con ciertos grupos nacionalistas surgidos en la ciudad y que, más adelante, confluirían en el peronismo. ${ }^{(19)}$

Esta minoría selecta fue proyectada a la esfera pública por la propia curia, lo cual mejoró su posición en la sociedad. Pero, a la vez, sus miembros, como hombres de la Iglesia, desde cada lugar ocupado, contribuyeron a acentuar la presencia de la institución en el ámbito local. A ello coadyuvó la política seguida por Monseñor Caggiano para el gobierno de la Diócesis de Rosario, desde 1935. Caggiano se valió de los dirigentes laicos que había frecuentado en sus conferencias y giras proselitistas, una década atrás, para impulsar la ACA en la ciudad, cambiar la dinámica de las actividades desplegadas hasta entonces por la $\operatorname{Iglesia}{ }^{(20)}$ y afirmar la presencia de ésta mediante la designación de sus hombres en diversos puestos, tanto como la difusión de su producción intelectual. $\mathrm{Al}$ surgir el peronismo, considerando que se abría una coyuntura que no debía desaprovecharse, ${ }^{(21)}$ adhirió decididamente al mismo, arrastrando en ello a sus incondicionales. ${ }^{(22)}$

En este marco, creemos de interés efectuar un análisis del catolicismo social en Rosario o, tal como lo denominaremos en adelante, del nacionalismo sindicalista católico - definido alrededor de 1930-, con el propósito de comprender cómo se construyó la derecha católica en la ciudad y cómo enlaza ésta, mediante su discurso 
y sus prácticas - aunque el tratamiento puntual de éstas excede las posibilidades del presente trabajo-, con diversos fenómenos políticos de relevancia.

Un elemento importante para ello, es que su dirigencia laica se ofreció como elenco de los sucesivos gobiernos, y se vinculó con las élites políticas y sociales, en el ámbito local, dispuesta a llegar "donde el Cardenal no podía llegar" y "donde el cura no podía o no debía llegar".(23) Se conformó así una élite cuya consistencia derivaba, más que de un determinado partidismo político, de una práctica institucional y de una ideología forjadas en el seno de la Iglesia Católica. En este sentido, el interés por su estudio no radica tanto en la originalidad de los planteos, sino en la forma en que va articulando un discurso autoritario en lo político, reformista en lo social y, en ambos casos, dispuesto a la confrontación. Ello permite analizar cómo se construyó, históricamente, el integrismo católico, en un espacio local determinado.

El tema escogido, por tanto, aporta a una relectura de la particular asociación entre nacionalismo, autoritarismo y reforma social que caracteriza al populismo. En este sentido, el catolicismo social rosarino, redefinido por la ACA y sujeto a las directivas de su Obispo, enlaza con el peronismo. A la vez que, por otro lado, su ideología política, su discurso y sus propuestas de control, lo vinculan también a los distintos gobiernos militares que dominaron la segunda mitad del presente siglo. Ello nos coloca, incluso, en la perspectiva de las ideas autoritarias del período posperonista. No hay que olvidar que, a partir de 1930, los cuadros dirigentes de la Iglesia, asociados a las élites políticas, se valieron del fortalecimiento de la relaciones entre la curia y el Estado, de recursos como la educación, la acción parroquial y la prensa, para acceder a franjas importantes de la población local. De este modo, su presencia se multiplicó en los espacios más diversos y desde ellos procuró construir una opinión católica, contribuyó a formar la cultura política de una parte significativa de la sociedad rosarina y, a su vez, coadyuvó a definir el rol decisivo que desempeñaría, en adelante, la Iglesia Argentina.

\section{La construcción de un nacionalismo sindicalista católico}

El estudio del catolicismo durante 1930-1946, nos ha permitido comprobar, desde una perspectiva ideológica, la existencia de una corriente que hemos denominado nacionalismo sindicalista católico. Este concepto, involucra la idea de un sindicalismo católico que se entrecruza con la ideología nacionalista vigente en los años' 30 .

El término sindicalismo católico tiene dos acepciones posibles. Por un lado, se refiere a la actividad desplegada por el catolicismo social en procura de llevar a la práctica un programa reformista que se asienta, básicamente, en la creación de sindicatos; por otro lado, designa una corriente ideológica que fue incorporando, en forma creciente y sistemática, cuestiones propias del movimiento nacionalista 
argentino, pero subordinadas a los imperativos de la reforma social. Por tal motivo, consideramos que la denominación de nacionalismo sindicalista católico resulta, también, apropiada. ${ }^{(24)}$

La década de 1930 introdujo elementos significativos para analizar la construcción de esta vertiente del pensamiento católico. En especial, el Golpe de Estado como alternativa política, en la Argentina contemporánea, resulta un factor relevante si se estudia la acción católica, su posicionamiento frente al poder político y su reinserción en la vida pública. En este sentido, el movimiento encabezado por el General Uriburu, representó el ascenso al poder de un sector de las Fuerzas Armadas identificado con el corporativismo, el nacionalismo y la Iglesia. Ello provocó una actitud favorable entre los católicos, la cual, a pesar de ciertas prevenciones iniciales, por las diferencias ideológicas que distanciaban a ambos presidentes, alcanzó también al gobierno de Justo y a sus sucesores. ${ }^{(25)}$

Según hemos visto, en Rosario, el socialcristianismo contaba con una trayectoria que le había permitido sostener periódicos, centros de propaganda, acción social e, incluso, sindical. Asimismo, desde 1916, fue portador de un discurso socio-político alternativo, prohijado por el Círculo de Obreros local. Sin embargo, a partir de 1930, aunque parezca paradójico, la defensa de la idea de democracia - concebida como democracia cristiana - coincidió con un alineamiento en favor del Gobierno Provisional. (26)

Desde entonces, el Círculo de Obreros de Rosario aprovechó las circunstancias propicias al catolicismo y procuró ejercer presión en dos sentidos fundamentales: pidiendo que se implementaran medidas para resolver los problemas del trabajo -desocupación, huelgas, bajos salarios-y exigiendo que el gobierno contuviera la difusión de ideas comunistas, regulando la acción de la prensa, de los órganos de educación y de la policía. ${ }^{(27)}$ El discurso católico expresaba también una exaltación del orden por contraposición al desorden a la última gestión radical. ${ }^{(28)}$ Sin embargo, aún permanecía atado a cierto criterio legalista, ya que destacaba el carácter provisional anunciado por el gobierno de facto. ${ }^{(29)}$

El rasgo distintivo del nacionalismo sindicalista católico - corriente que nos interesa analizar - radicaba en la subordinación de lo político a las cuestiones económico-sociales. A partir de 1929-1930, su preocupación principal se centró en la crisis económica que se prolongaría varios años, en la falta de una política social suficiente y en la permisividad ideológica que, según se creía, era propia del demoliberalismo con que se regían las instituciones de la República. Desde entonces, sus demandas sociales se combinaron con otras de orden político que, en la práctica, significaban un cercenamiento de las libertades individuales consagradas por la Constitución.

A esta actitud contribuyeron, además, condicionantes de índole internacional. Al promediar el período, la guerra civil española y el reforzamiento de los modelos nazi-fascistas europeos, proporcionarían el marco adecuado para definir la posición del catolicismo social rosarino en su prédica anti-comunista. Por esos años, 
España se había convertido, para los nacionalistas, en el punto de polarización entre el fascismo y el "frente rojo". Muchos veían en el franco-falangismo "una versión estrictamente católica del fascismo".(30)

La prensa católica local se hacía eco de esta interpretación, afirmando que, en España, era cada vez más explícito el peligro que representaba la propagación del sovietismo tanto para la humanidad como para la Argentina. ${ }^{(31)}$ Se alimentó así e' temor por la presencia del comunismo en el país, acentuándose la propaganda en su contra entre los meses de octubre y diciembre del año '36. ${ }^{(32)}$ Esta prédica antimarxista, según creemos, estaba estrechamente vinculada a la defensa de la tradición católica de la hispanidad, en cuyo contexto se carga de significado un discurso donde se asocian ideas tales como complot masónico, anticlericalismo, revolución y sovietismo. Su efecto inmediato sería, entonces, la demanda de un control riguroso por parte del Estado. (33)

Durante la década de 1930, por consiguiente, los católicos sociales acentuaron su intransigencia frente a la difusión del comunismo pues lo consideraban una ideología destructiva de la nacionalidad, del orden y de los valores cristianos. Sin embargo, algunos temas particulares seguían manteniéndolos al margen del nacionalismo católico más conservador, diferenciándolos, a pesar de su credo político crecientemente autoritario. Por su parte, los distintos gobiernos vieron en algunas figuras católicas y en sus instituciones sociales, canales apropiados que permitirían poner coto a las ideas revolucionarias que se difundieran en el país, generando expectativas recíprocas que - a largo plazo- restituirían a la Iglesia un espacio de poder antes perdido.

Partiendo de este contexto, en adelante, nos proponemos acercar un análisis del discurso político y social que caracterizó al nacionalismo sindicalista católico rosarino de los años ' 30 , con miras a comprender los vínculos establecidos con el Estado y los precedentes que explicarían la posición asumida frente al peronismo. Su pensamiento se vehiculizó, en gran medida, a través del periódico La Verdad, órgano oficial del Círculo de Obreros de Rosario. En consecuencia, nuestro trabajo se centrará en esta publicación, por varias razones. En primer lugar, porque $\mathbf{L a}$ Verdad expresaba la opinión de una institución que resulta clave para comprender el socialcristianismo rosarino; en segundo lugar, porque logró gran continuidad en el ámbito de la prensa local, ya que se publicó sin interrupción desde 1920 hasta el fin del período escogido; y, finalmente, porque las orientaciones que sigue son coherentes con postulados que, entre 1928 y 1931, expresaban otras publicaciones católicas, como El Heraldo - editado en Rosario bajo el auspicio del Obispo diocesano-y el Boletin Eclesiástico de la Diócesis de Santa Fe. (34) 


\section{La Iglesia Católica como agente de control ideológico}

Tanto para los católicos como para otros sectores de la sociedad, el socialismo era el primer paso hacia el comunismo de modelo soviético. Comenzó a generalizarse entonces, quizás con el fin de polarizar posiciones, el uso de la palabra comunismo para englobar al socialismo, al anarquismo y a la izquierda en general. Asimismo, en el ámbito del gobierno, puede comprobarse una preocupación análoga a la que se registra entre los católicos, respecto de las ideas y actividades de la izquierda. En 1934, por ejemplo, llegó a manos del Presidente Justo un plan de "campaña antisocialista" de vasto alcance. Nos interesa detenernos en él ya que otorgaba un rol significativo a dirigentes y estructuras católicas. El proyecto proponía una campaña de carácter "apolítico en lo electoral" y de alcance nacional, acompañada de una intensa labor publicitaria. ${ }^{(35)}$ La acción se diseñaba desde diversos campos: el político, que correspondía a los partidos no socialistas; el intelectual, que proponía el acercamiento de figuras relevantes; el religioso, que involucraba a ciertas instituciones católicas; las fuerzas vivas, que debían encargarse del financiamiento de la campaña; y la posible creación de un "Instituto Antimarxista”, destinado a formar propagandistas especializados. (36)

El autor de la propuesta sugería la participación de ciertas personas por su "volumen dentro del campo del pensamiento católico, insospechables de interés electoral y de actuación probada en muchos años de luchas antimarxistas de distinto orden". ${ }^{(37)}$ Se mencionaba entonces a los Monseñores De Andrea y Franceschi, vinculados al sector socialcristiano que se impusiera en los años '20, luego de desplazar definitivamente a los grupos que se mostraban proclives a desarrollarse con relativa autonomía del clero, admitiendo la posibilidad de tejer alianzas coyunturales con grupos y sectores ajenos a la Iglesia. Los obispos mencionados y Monseñor Dionisio Napal - también citado- tenían amplia experiencia en las conferencias callejeras practicadas por los católicos desde comienzos de siglo. Finalmente, se apelaba a laicos de extracción diversa, entre quienes puede destacarse a Arturo Bas y Gustavo Martínez Zuviría. ${ }^{(38)} \mathrm{El}$ primero, vinculado al radicalismo cordobés, daría cierta perspectiva democrática en contraste con la figura cerradamente nacionalista de Martínez Zuviría.

En el plano institucional, se aclaraba que "las autoridades eclesiásticas pueden y deben tener una actuación preponderante". (39) En este sentido, se consideraba que la Acción Católica - recientemente fundada- sería de utilidad para el gobierno pero, a la vez, su colaboración le permitiría darse a conocer, afianzando su presencia en el país. Por su parte, los Círculos de Obreros podrían encargarse de las conferencias callejeras, en las que ya estaban experimentados, beneficiándose con nuevos adherentes. También se pensaba en un moderno apostolado que podrían implementar las Juntas de Jóvenes y Señoritas de Acción Católica en oficinas, talleres y fábricas. $(40)$ 
En consecuencia, el plan parecía proponer un promisorio intercambio: si esas figuras e instituciones católicas colaboraban con el gobierno, obtendrían la posibilidad de darse a conocer en forma masiva y de conseguir nuevos prosélitos, reconquistando el espacio perdido en épocas precedentes. Sin embargo, la forma de orquestar la participación de los católicos recreaba cierta raíz maurrasiana en su concepción de fondo. Así, la Iglesia aparecía instrumentalizada por el poder político para fines de control social, en sentido amplio, y de control ideológico, en lo que a este proyecto concreto se refiere. Se la consideraba, entonces, una institución de orden y jerarquia que, mediante su participación, ocuparía un lugar preponderante en el nuevo esquema de poder que se intentaba construir.

\section{Las demandas católicas}

Desde la perspectiva católica, existía una reciprocidad manifiesta hacia la propuesta autoritaria que se generaba en ciertos ámbitos de gobierno, tal como vimos precedentemente. El temor a la difusión de ideas revolucionarias, la influencia ejercida por dictaduras de la derecha europea y los conflictos latentes en la sociedad argentina, habían inclinado al catolicismo social hacia una demanda constante en favor de medidas que reforzaran el control estatal.

La Verdad sostenía que era necesario defender el concepto de nacionalidad, que se vinculaba a los valores tradicionales del cristianismo. En este sentido, exaltaba las expresiones "netamente nacionalistas" de altos funcionarios de la República, entendiendo que el nacionalismo católico no era "excluyente", pues la sociedad argentina aceptaba en su seno "a todos los hombres del mundo que quisieran convivir la existencia argentina, dentro de sus postulados políticos, y jamás, para que llegaran en empresa de conquista". ${ }^{(41)}$ Este comentario se refiere, ante todo, a los inmigrantes extranjeros que militaban en organizaciones y partidos de izquierda. Así, ese mismo año, el periódico pedía la aplicación de la Ley de Residencia para seleccionar la inmigración y expulsar a aquellos extranjeros considerados perjudiciales para el Estado argentino. Para definir su posición al respecto, el periódico concluia: “..... No queremos los rusos, resacas de otros países, echados de otros lados, y que vienen a la República para trabajarla، con el oro que se les manda de Rusia! La entrada libre al obrero trabajador y honesto que viene a nuestra patria a trabajar. Que la promesa generosa del preámbulo de nuestra Carta Magna, no sea tergiversada. Libertad para todo y para todos, menos para el mal y sus malhechores."(42)

En estas expresiones quedaban patentizadas las ideas sobre el inmigrante que militaba en grupos de izquierda. Eran asalariados de la Rusia Soviética, expulsados de los paises que defendían su soberanía, que se aprovechaban de la generosidad de nuestra Constitución para instalarse con fines propagandísticos revolucionarios. En última instancia, eran sinónimo de mal y delincuencia. Sobre ellos, por tanto, 
correspondía la aplicación de la polémica Ley de 1902, la cual habilitaba al Estado argentino a expulsar extranjeros, por razones ideológicas, cuando lo considerara oportuno. ${ }^{(43)}$ También correspondia, desde esta óptica, implementar un control policial más riguroso. La referencia a los "activistas" de izquierda como "delincuentes" que ponian en riesgo el orden social sería constante a lo largo del período y, particularmente, a partir de 1942-43, cuando los sucesivos gobiernos encararan firmes medidas de "profilaxis social".(44)

A la identificación de la inmigración rusa como peligrosa, corresponde agregar la judía. Ya en 1929, algunas publicaciones católicas identificaban a la Rusia Soviética con la acción internacional de los judíos. Por un lado, se afirmaba que ellos habian participado activamente en la revolución de 1917.(45) Pero, a la vez, se sostenía que los judíos tenían particular interés en destruir el orden del mundo cristiano, razón por la cual eran aliados naturales del comunismo, la masonería y el capitalismo internacional. ${ }^{(46)}$ Se rechazaba, es verdad, la difusión de un antisemitismo radical, pero se aclaraba que debía procurarse "apartar al país del peligro judío, como fuerza secreta revolucionaria que nadie puede negar".(47)

Mediante su poder financiero, se vinculaba a los judíos con los movimientos destinados a destruir el orden cristiano. Esta idea, actualizada, revela cierta proximidad con una extensa tradición hispánica sobre el tema. Tradición cultural en la que también abrevó el nacionalismo argentino. Sin embargo, la solución al problema judio no era un antisemitismo extremo que implicara la eliminación física, por ejemplo, sino que se proponía la creación de un Estado Sionista en algún lugar del mundo, a fin de neutralizar una acción oculta considerada perniciosa. ${ }^{(48)}$

De este modo, siguiendo la tendencia iniciada a fines de la década del ' 20 , en el discurso católico social aparecían indiferenciados los conceptos de ruso-judío-comunista-capitalista-masón, en un confuso cuadro ideológico que imbricaba cierta forma de antisemitismo y un anticomunismo radical, fundiéndose ambos en nociones nacionalistas y anti-imperialistas relativamente más sistemáticas. ${ }^{49}$ ) Tal vez pueda atribuirse esta falta de sistematicidad a una cultura política débil y fuertemente influida por movimientos político-ideológicos de carácter internacional, que ponían en crisis al mundo de entreguerras.

\section{La acción del Estado}

Dentro de esta línea de pensamiento, el periódico La Verdad se hacía eco de una memoria elaborada por la policía, en 1931, para el "estudio de las actividades del comunismo". (50) Al respecto, se legitimaba la intervención policial en una cuestión que, según el articulista, "se ha convertido en una preocupación internacional".(51) Se consideraba que en el país existían "agentes subvencionados por el sovietismo" que nada tenían que ver con los verdaderos intereses obreros. Por el contrario, sólo eran "agitadores profesionales" que querían consumar la revolu- 
ción, a fin de construir, en la Argentina, un orden social análogo al soviético. ${ }^{(52)}$ Estos agitadores, esta infiltración comunista, ponía en peligro la continuidad de la sociedad preexistente y, como "destruir sin capacidad para construir es peor que dejar en pie un edificio". Y, como "...la idea de nación y el sentimiento de patria se alimentan con nociones de orden social", era necesario que interviniera el Estado a través de sus órganos de seguridad para sostener un orden que, aunque imperfecto, guardaba una identidad propia. ${ }^{(53)}$ Yesta identidad estaba asociada a la idea de Dios: "en la misma medida que el pueblo va debilitando en su espíritu el sentimiento religioso, va abdicando del sentimiento patriótico. A menos religión, menos amor a la patria......sin Dios no puede haber patria".(54)

En consecuencia, resultaba apropiado que la Policía creara un "Órgano de Defensa Nacional contra el comunismo", cuyo objetivo sería informar al pueblo sobre sus peligros, a la vez que vigilaría y protegería al país de la "actividad de los agitadores profesionales". (55) La lucha contra el comunismo contribuiría, por tanto, no sólo a la defensa del orden social vigente, sino también de la nacionalidad que lo sostenía. Y, asimismo, del cristianismo insito en ella. La lucha se volvía, entonces, un imperativo patriótico. Esto revela la afinidad existente entre este sector del catolicismo social y los proyectos que, en diversos organismos de seguridad, se venían elaborando durante el período de la restauración conservadora. Por esta razón, en 1936, el periódico rosarino aplaudía la iniciativa del Poder Ejecutivo Nacional tendiente a sancionar una ley que reprimiera el comunismo. ${ }^{(56)}$

Para el pensamiento católico, la asimilación entre la ideología de izquierda y la delincuencia se proyectaba también a otras esferas. Por consiguiente, debía ejercerse un control más estricto al respecto. Por un lado, "vigilar" el sistema educativo y lo que éste transmitía. La función formadora de ciudadanos correspondiente a la educación pública estaba peligrando, se decía, por la presencia de docentes "de izquierda" en el sistema, lo cual era resultado de la permisividad de los organismos gubernamentales. Se afirmaba que "el peligro en la escuela es tanto por la acción directa como por la omisión deliberada de educar a los educandos en conceptos de orden y de patria". Y se agregaba "con no explicar o explicar torcida y tendenciosamente la idea de nacionalidad ya se ha sembrado un germen disolvente. Si el germen se enquista, se obtendrá un ciudadano apático. Si el germen fructifica, reventará el descontento activo contra las instituciones patrias".(57)

Por consiguiente, la presencia de educadores con determinadas ideologías, particularmente anticlericales, ponía en peligro la nacionalidad y el espíritu patriótico, a la vez que dejaba abierto el camino para la formación de nuevas generaciones indiferentes a los problemas nacionales o, en el peor de los casos, con tendencias revolucionarias. Se decía, entonces, que era preciso vigilar permanentemente la escuela pública, tanto por parte de las autoridades competentes como por parte de aquellos ciudadanos - argentinos, naturalizados o extranjeros- que quisieran preservar los valores y la idiosincracia nacionales, estimulando incluso la delación. ${ }^{(58)}$ De esta forma, la discriminación respecto del extranjero no pasaba por su 
condición de tal, o por su mayor o menor pobreza, sino por la ideologia que lo pudiera identificar. ${ }^{(59)}$

Esta prevención respecto de la escuela laica, definida como escuela atea, no era nueva, sino que estaba presente desde la sanción de la Ley 1420, de educación común, en 1884. Tampoco era original la idea de que la escuela debía formar al ciudadano en los valores patrios. Sin embargo, la demanda de control que se plantea y los mecanismos de vigilancia sugeridos exceden - por su intransigenciael discurso de las figuras que, en nombre de la institución eclesiástica, argumentaban públicamente en favor de la libertad de enseñanza. ${ }^{(60)}$

No sólo el sistema educativo estaba en la mira de los católicos sociales. También la prensa debía sujetarse a controles más estrictos. En este sentido, se decía que el Estado debía limitar la libertad de prensa, pues ella lesionaba la "salud moral" de la sociedad. ${ }^{(61)}$ Se afirmaba, entonces, que la pluma de algunos periodistas, constituía un arma que les permitía erigirse en "delincuentes de lesa sociedad". (62) Por lo tanto, la libre expresión, sin una legislación restrictiva, era interpretada como una forma de delincuencia que destruía los lazos sociales más firmes. Por esta razón se solicitaban leyes que le pusieran coto. ${ }^{(63)}$ La confrontación de artículos diversos nos induce a pensar que, en este caso, se alude a la difusión de ideologías consideradas disolventes y que tendían a subvertir el orden establecido. De esta forma se reforzaba la noción de que las prédicas del comunismo, o de ciertas tendencias socialistas y liberales, eran equivalentes a la delincuencia común y como tal debian ser tratadas por las autoridades.

Incluso, se llegó a proponer un recorte de los derechos constitucionales, con el objeto de detener los "avances de la delincuencia erigida en sistema doctrinario": "Nuestra Carta Magna acuerda (a) todos los habitantes el derecho (de) expresar libremente sus ideas, pero sería una insensatez pensar que ese derecho no tiene una limitación. Nuestros constituyentes, al plasmar nuestra constitución libérrima y generosa no han podido columbrar la aparición en el porvenir de la fuerza antisocial y antinatural que constituye el comunismo...".(64) Es evidente que se consideraban válidas todas aquellas disposiciones que trataban de frenar las tendencias que cuestionaban el orden imperante en la sociedad. Así, el catolicismo social rosarino, además de mantener una propuesta corporativista que, desde la década anterior, contemplaba la posibilidad de restringir la participación política - voto calificado-, ${ }^{(65)}$ avanzaba ahora en favor de medidas inmediatas que aseguraran el cercenamiento de las garantías individuales que establecía nuestra Constitución. En este sentido, por ejemplo, se llegó a proponer un control riguroso de la correspondencia privada para evitar la difusión de "ideas comunistas" a través del correo oficial. ${ }^{(66)}$ Mientras, originariamente, la corriente social había priorizado la reforma socieconómica y, en este sentido, solía enfatizar el rechazo del liberalismo económico, en los años '30 reforzó su ataque al liberalismo político, negando sistemáticamente la legitimidad de sus principios esenciales. Es decir, avanzó en un 
sentido que exigía la restricción legal del concepto de ciudadanía implícito en nuestras leyes.

\section{Católicos y organización obrera}

La permanente demanda en favor de un mayor control estatal sobre las actividades revolucionarias no afectaba, se decía, a la organización obrera. Por el contrario, en ningún momento estos católicos sintieron que se apartaban de sus objetivos sociales. Mantuvieron una constante interpelación a los poderes públicos cuando juzgaron que peligraban ciertos logros de los trabajadores ante las presiones patronales e, incluso, el vocabulario que emplearon resultó, en ocasiones, significativamente frontal. (67)

Asimismo, no abandonaron la propaganda en favor de la asociación obrera cristiana, resaltando los beneficios que ofrecían los sindicatos mixtos - de obreros y patrones-o, en su defecto, las más viables comisiones mixtas paralelas - obreros y patrones organizados en forma independiente- para resolver los conflictos laborales de un gremio determinado. ${ }^{(68)}$ Sin embargo, durante la década de 1930 , los católicos sociales no lograron constituir sindicatos confesionales sólidos. A pesar de la prédica de los Círculos de Obreros a través de sus congresos, recién después del último de ellos, hacia 1942-43, se comprueban iniciativas concretas al respecto.

En el plano de las ideas, estos católicos sostuvieron que "el capitalismo hace la guerra a la familia, por la misma razón que impulsó a hacer la guerra a las asociaciones obreras.....El capitalismo quiere el colectivismo para sí y el individualismo para los obreros......quiere que los capitalistas estén unidos para la lucha, y que los obreros estén dispersos". (69) De este modo, siguiendo los postulados de la Quadragesimo Anno, manifestaban su oposición a las entidades patronales - "capitalismo"- que querían la atomización de la clase obrera, mientras se fortalecian a sí mismas, reforzando la presión contra el proletariado. ${ }^{(70)}$ Un cambio corroborado en estos años es que, por primera vez, en Rosario, se producía una reacción decidida contra la política laboral de una importante empresa cerealera. Al promediar la década, el Círculo de Obreros de Rosario se enfrentó a Minetti y Cía. catalogándolo de "caso típico de prepotencia capitalista".(71)

El caso de Minetti, sin ser el único, resulta el más significativo del período. El conflicto se originó en el despido de un grupo de trabajadores que reclamaban por el incumplimiento de un pliego de condiciones pactado previamente. Según el relato del Círculo, la empresa tendió una trampa para cesantear a los obreros disconformes, entre quienes se encontraban algunos de sus socios - Roberto Castro, Antonio Marzin, Federico Smania, Eugenio Gasparotto, Carlos A. Silva, Angel Contini, Francisco Araguas, Nicolás Arena, Juan Vicich, Carlos Picone y Natalio Yakas-. En consecuencia, la institución inició las gestiones para lograr su reincorporación. ${ }^{(72)}$ 
De esta gestión surgió un enfrentamiento entre el Círculo - que se presentaba a sí mismo como "institución de orden", para no confundirse con sectores que consideraba "revolucionarios"-, y la empresa, que no sólo ignoraba las demandas interpuestas en nombre de los cesanteados, sino que, según se interpretaba, tergiversaba los hechos que habian conducido al conflicto en cuestión. (73) Lo que llama la atención es el lenguaje confrontacionista empleado. Evidentemente, al considerarse institución de orden, el Círculo de Obreros se creía interlocutor privilegiado ante los patrones, procurando actuar como mediador legítimo en el conflicto. Por el contrario, la empresa priorizaba los intereses propios, sin preocuparle quién gestionaba en nombre de los obreros.

El Círculo explicaba la arbitrariedad patronal por la insuficiente legislación sobre los problemas de trabajo. En tal sentido, afirmaba que, si bien no era común que todas la empresas llegaran a los límites de Minetti, se había comprobado: "a) que un patrono.....puede, aún contra toda razón y justicia, y violando los más elementales derechos humanos, dejar en la calle, en cualquier momento, a centenares de obreros.....; b) que el mismo patrono puede - abusando inicuamente de la difícil situación económica actual- disponer de obreros que se ven precisados a aceptar salarios de hambre".(74) $\mathrm{El}$ texto, aunque evitaba generalizar su juicio, consideraba que la exigua legislación existente creaba las condiciones para el abuso de los capitalistas, violando derechos que denominaba "humanos" y que eran, por tanto, de carácter elemental, esenciales a la dignidad de los trabajadores.

El conflicto de Minetti y Cía. nos sitúa en la perspectiva del catolicismo social rosarino, el cual, mientras seguía un rumbo crecientemente autoritario en lo político, expresaba una mayor frontalidad en sus planteos sociales. Además, consideraba necesario estimular la organización del obrero cristiano, entendiendo que ello fomentaría la colaboración entre las clases sociales y permitiría controlar al comunismo, a cuya acción sindical atribuía caracteres revolucionarios. Pero ese control -se decía- no afectaba a los obreros "verdaderos", sino sólo a los "activistas profesionales". Por tanto, de organizarse sindicatos cristianos, los obreros se incorporarían a ellos y dejarían de depender de los sindicatos revolucionarios. ${ }^{(75)}$ Finalmente, en lo posible, el sindicalismo cristiano debía funcionar a través de sindicatos mixtos, planteo que, en general, se había abandonado a comienzos de siglo. Sin embargo, admitida la resistencia de los trabajadores a unirse con los patrones en un mismo organismo, estos católicos consideraban igualmente eficaz la constitución de comisiones mixtas paritarias. ${ }^{(76)}$

\section{El surgimiento del Peronismo}

El Golpe de 1943 generó expectativas positivas en el Círculo de Obreros de Rosario. Por un lado, se esperaba una depuración de la vida política cuyos índices de corrupción, se decía, iban más allá de los errores de algún partido en particular, 
pues alcanzaba a todo y a todos. ${ }^{(77)}$ Por otro lado, se exaltaba la implementación de medidas de mayor control ideológico, especialmente las orientadas contra las actividades "comunistas" y contra ciertas libertades individuales, como la libertad de expresión. ${ }^{(78)}$ En tercer lugar, se destacaba el vuelco evidente que el gobierno estaba dando en favor de los intereses de la Iglesia, sobre todo en cuestiones de educación y familia, a lo que se unía el deseo de aumentar la presencia estatal en las áreas de economía y trabajo, aunque preservando los intereses particulares. ${ }^{(79)}$ Finalmente, se avalaba la política de neutralidad adoptada frente a la Segunda Guerra Mundial. ${ }^{(80)}$ Con el gobierno de facto, entonces, se abría la posibilidad de consolidar los vínculos de la Iglesia con el Estado, mejorando su posición dentro de la sociedad.

En 1942, un año antes del golpe, los Círculos de Obreros y la Acción Católica habian comenzado a llevar a cabo las primeras iniciativas concretas con el fin de crear y consolidar sindicatos cristianos. ${ }^{(81)}$ Para ello siguieron los lineamientos definidos por el Primer Congreso de Católicos de América Latina, de 1919, que propugnaba sindicatos confesionales y con autonomía del Estado - denominados "sindicatos libres"- ${ }^{(82)}$ La consideración de ambos aspectos será relevante para explicar las primeras actitudes asumidas por el catolicismo social frente a la figura de Perón.

Hacia 1944, la situación parecía promisoria. El periódico La Verdad de ese año, exaltaba la solución socialcristiana ofrecida por Perón a los problemas obreros. En su carácter de Secretario de Trabajo y Previsión Social, había recomendado a trabajadores en conflicto que se organizaran para conseguir contratos colectivos de trabajo. Los católicos decían que esta alternativa, propia del socialcristianismo, llevaba implícita la formación de sindicatos paralelos ${ }^{(83)}$ que pudieran concertar tales convenciones, bajo la fiscalización del Estado. ${ }^{(84)}$ Desde su perspectiva, la Secretaría estaba incorporando mecanismos que coincidian con el principio católico de armonía o colaboración entre las clases sociales. ${ }^{(85)}$ Además, los católicos rosarinos afirmaban que la política social arbitrada por Perón, durante su primer año de gestión, constituía "una nueva esperanza en los trabajadores.....".(86)

Sin embargo, La Verdad también exteriorizaba ciertas prevenciones. A su juicio, existía la posibilidad de que la dirigencia sindical de izquierda aprovechara las circunstancias y construyera vínculos con el gobierno para mantener en sus manos el poder sindical, pues estaban habituados a las prácticas negociadoras con este fin. ${ }^{(87)}$ En realidad, implicitamente, se procuraba presentar al sindicalismo cristiano como único interlocutor válido frente al Estado. ${ }^{(88)}$

A principios de 1945, un conflicto producido en la ciudad de Córdoba cortó las expectativas auspiciosas de los rosarinos. El Círculo de Obreros de aquella ciudad había denunciado que, en ésa y otras localidades del país, habría una consigna gubernamental para "eliminar todo contenido espiritual en la vida de nuestros gremios", agregando que la delegación regional de la Secretaría de Trabajo se había apoyado en la CGT local, a la cual se negaba legitimidad en la representación 
de los intereses de la totalidad de los obreros. ${ }^{\left({ }^{89}\right)} \mathrm{El}$ reclamo católico nunca tuvo respuesta oficial.

A ello debe añadirse el decreto 23.852, del 2 de octubre de 1945, sobre asociaciones profesionales. Dos de sus artículos afectaban particularmente el proyecto de sindicalismo confesional de los católicos. El noveno establecía que, "en el caso de existir un sindicato con personalidad gremial, sólo podrá concederse esa personalidad a otro sindicato de la misma actividad, cuando el número de afiliados cotizantes de este último.....fuera superior al de los pertenecientes a la asociación que goce de personalidad gremial". ${ }^{(90)}$ Yel artículo 22, negaba la personería a "las asociaciones profesionales que se constituyan, diferencien o denominen en base a religiones, credos, nacionalidades, razas o sexos".(91)

Ambas disposiciones excluian la posibilidad de generar un sindicalismo católico "autónomo". En el caso del primer artículo citado, porque el sindicalismo confesional era casi inexistente y, para desarrollarse, necesitaba una arnplia libertad en las normas de creación de sindicatos, a fin de favorecer la legalización de aquéllos que contaran con pocos asociados; en el caso del segundo, porque en los años ' 40 , la tendencia del catolicismo social era crear sindicatos confesionales, que explicitaran su profesión de fe. Además, por entonces, los únicos sindicatos de este tipo que funcionaban regularmente, no sólo se denominaban "católicos" sino que eran de carácter femenino como, por ejemplo, el de costureras, el de empleadas católicas y el de enfermeras. ${ }^{(92)}$

Evidentemente, el interés del gobierno por unificar la acción sindical, acrecentando su injerencia, fue interpretado como un ataque directo al sindicalismo católico que daba sus primeros pasos luego de años de inacción. Este roce inicial puso en evidencia tácticas divergentes que, en adelante, serían dificiles de conciliar. Los católicos sociales - por afinidad ideológica - aspiraban a constituirse en nexo entre el gobierno y los obreros, dentro de la política arbitrada por Perón. Sin embargo, en la práctica, carecian de un arraigo sindical efectivo. En cambio, la actitud del Secretario de Trabajo puede explicarse sopesando las ventajas que ofrecía cada parte. Mientras los viejos dirigentes sindicales podían proporcionarle las estructuras necesarias para hacer pie en el movimiento obrero, el socialcristianismo podría acercarle únicamente una doctrina que, no sólo resultaba prescindible, sino que tampoco parecía conocer en profundidad. ${ }^{(93)}$

Entre 1944 y 1945, Perón optó por fortalecer vínculos con importantes sectores de la dirigencia sindical anterior, a la vez que, en sus discursos, comenzó a apelar a la Doctrina Social de la Iglesia. Sin embargo, esta apelación del primer momento era, sobre todo, un recurso para legitimar su política social ante los empresarios, más que para agradar a la institución eclesiástica. ${ }^{(94)}$ Asimismo, dentro de la acción global de la Iglesia, este tema tenía un carácter subordinado, pues la Jerarquía estaba más preocupada por el control de la educación. En realidad, la reforma social sólo era considerada prioritaria por un sector reducido del laicado, que provenía de la militancia socialcristiana. 
Una vez en la presidencia de la República, Perón cerraría el ciclo iniciado con la presión sobre los sindicatos que no aceptaron someterse a sus directivas -entre los cuales se sintieron incluidos quienes intentaban crear sindicatos confesionales-, apropiándose de elementos de origen diverso, entre ellos, de la ideología democristiana, pero despojándolos de todo matiz religioso. ${ }^{(95)}$ A partir de ese momento, ciertas ideas socialcristianas serían reivindicadas por el Peronismo, contribuyendo, en parte, a dar nuevo contenido a la ideología del movimiento obrero argentino. ${ }^{(96)}$ Recién entonces la Doctrina Social de la Iglesia alcanzaría una proyección que, por sí misma, no había logrado antes. ${ }^{(97)}$ Finalmente, el surgimiento del peronismo dejaba trunco el último intento de un sindicalismo confesional "autónomo", provocando una sangría dentro del catolicismo social, cuya evidencia sería notable a medida que se consolidaba el Estado peronista.

En síntesis, a pesar de las expectativas positivas del comienzo, mientras los católicos sociales defendían, en 1945, sindicatos confesionales autónomos, el gobierno - a pesar de las marchas y contramarchas- prefería estrechar vínculos con aquellos dirigentes socialistas y sindicalistas dispuestos a negociar y proporcionar una base de sustentación a la nueva política estatal. Intentaba reforzar, de este modo, su posición dentro de la élite militar y frente a la resistencia del sector civil democrático. ${ }^{(98)}$ A ello se suma el desplazamiento de los sindicatos que permanecieron en la oposición. El objetivo era, entonces, lograr una homogeneidad que, desde la perspectiva estatal, revertía en un mayor control de las organizaciones obreras.

Por su lado, en el ámbito estrictamente sindical, los católicos tenían una doctrina sin dirigencia reconocida y, en este sentido, sus bases sociales eran débiles, lo cual los volvía una fuerza que podía ser absorbida o dispersada fácilmente por el gobierno. Carecían, asimismo, de sindicatos sólidos en el plano nacional, siendo inexistentes en el ámbito local ${ }^{(99)}$ - al contrario de lo que sucedía con los sectores de la dirigencia obrera que se unió a Perón-, pero contaban con una sólida organización asistencial que, en parte, fue asimilada por el Estado, en el período siguiente.

En consecuencia, el balance de los tres años de régimen militar, pone de manifiesto cierta intransigencia de los católicos sociales respecto del movimiento obrero - basada en cálculos políticos erróneos-, que contrastaba con la tendencia a la negociación exhibida por Perón frente a los gremios que no se le opusieron frontalmente. A lo que se añade su capacidad para movilizar a las masas populares, la cual quedó patentizada el 17 de Octubre de 1945 y, luego, durante de la campaña electoral que lo llevaría al poder. ${ }^{(100)}$

Estos factores condujeron a la pérdida del espacio sindical que el catolicismo social creía le estaba predestinado. Por otro lado, para imponer su proyecto de sindicalismo cristiano, el catolicismo hubiera necesitado una acción decidida del Estado en su favor, como había sucedido en el Brasil.(101) A partir de 1945, se comprueba cierto mutismo del Círculo de Obreros de Rosario respecto del peronis- 
mo. Este cambio puede explicarse por el acercamiento de Perón a algunos sindicalistas de izquierda y por la coacción ejercida sobre aquellos sindicatos que le eran hostiles, o que procuraban preservar su autonomía, afectando indirectamente al sindicalismo católico. Pero también debe considerarse la expectativa que generaron los acontecimientos posteriores al 17 de Octubre y la escisión que provocaron dentro del propio catolicismo social. Con ello se estaban sentando las bases de una relación política conflictiva donde quedaban latentes las aspiraciones hegemónicas del catolicismo social. ${ }^{(102)}$

De todos modos, conviene aclarar que la situación ahora se presentaría más compleja: mientras una parte del catolicismo social identificaría al nuevo régimen con el fascismo, asumiendo una actitud crítica, otra parte, de inclinaciones filo-fascistas, se adheriría abiertamente al peronismo provocando enfrentamientos que confluyeron críticamente en el año ' 54 . A pesar del retroceso de las tendencias democráticas que hemos analizado, Rosario no sería ajena a esta escisión. No hay que olvidar que el Estado mussoliniano absorbió -o desplazó mediante la coacción- las estructuras sindicales y políticas que tenía la democracia cristiana en Italia. En consecuencia, un sector del catolicismo social argentino, vinculado al proyecto de un Partido Popular o democristiano, vería con recelo la política implementada desde el Estado peronista, al establecer analogías entre ambos fenómenos. ${ }^{(103)} \mathrm{El}$ otro grupo, por el contrario, fracasados algunos intentos sindicales y político-partidistas llevados a cabo en los años precedentes, consideró que ese vacío podía llenarse a través del peronismo. El caso de Rosario resulta, en este sentido, significativo. Si bien los dirigentes de la ciudad, durante las décadas anteriores, se habian vinculado estrechamente a los demócratas del Partido Popular - en el plano nacional e internacional-, la actitud del Obispo Caggiano provocó que el grueso de sus cuadros se alineara con el Peronismo, a pesar de existir disidencias entre católicos no militantes, o en figuras de prestigio para el catolicismo social, como el salesiano Carlos Conci. (104)

\section{Conclusiones}

El período que va de 1930 a 1946 puso de manifiesto la existencia de un sindicalismo católico que acentuaba crecientemente sus tendencias integristas y autoritarias. En realidad, durante el período 1912/16-1926, marcado por la sanción de la Ley Sáenz Peña y el ascenso de los radicales al poder, el catolicismo social rosarino había expresado un pensamiento más plural. Sin embargo, a partir de $1927 / 28$, quizás preocupados por la reedición de la experiencia yrigoyenista, sus ideas comenzaron a rigidizarse, hasta que el autoritarismo se volvió particularmente explícito luego del Golpe de Uriburu, en 1930.

A partir de entonces, el periódico La Verdad sostuvo una demanda recurrente de control político-social orientada, ante todo, a lograr cierta homogeneización 
ideológica. A la vez, desarrolló una prédica propicia a los intereses obreros utilizando, incluso, un tono marcadamente crítico. Retomó también la idea de organizar a los trabajadores bajo su égida, como un objetivo clave para su acción. En este sentido, un elemento a su favor fue que, durante los gobiernos de Uriburu y Justo - a pesar de las diferencias que guardaban entre si- la Iglesia institucional había logrado recomponer sus relaciones con el Estado, mejorando su posición en las esferas de poder. Por otro lado, el proceso abierto por el Golpe del '43, con un control decidido sobre la educación, la prensa y el comunismo, fue recibido con optimismo por parte de los católicos. Sin embargo, su grado de inserción popular, a través de la acción sindical, siguió siendo limitado.

Este cuadro permite explicar cómo se veía a sí mismo el sindicalismo católico y qué objetivos perseguía. Por un lado, expresaba la intención de disciplinar, organizar, canalizar el movimiento obrero a partir de un estrechamiento de sus vínculos con el Estado procurando, de este modo, desplazar a la dirigencia sindical preexistente; por otro lado, sostenía la necesidad de producir un cambio entre los trabajadores, imponiendo la propia ideología. En esta problemática debe buscarse el punto de enlace pero también el de fricción entre socialcristianos y peronismo. En el fondo, ella ponía en juego la confesionalidad y la "autonomía" de los sindicatos cristianos. Hasta 1945, estos atributos eran considerados esenciales por el conjunto de los católicos sociales, pues deseaban conquistar un espacio en el mundo obrero y mediar en sus relaciones con el Estado, pero afirmando la autonomía y preeminencia de los sindicatos propios, todavía débiles o inexistentes.

Pero, a partir de este momento, comienzan a distanciarse las tácticas de la Jerarquía y las del grueso de los laicos vinculados al proyecto socialcristiano. Mientras éstos aspiraban a controlar la dirección del movimiento obrero - sin recursos reales, pues carecían de significación en el ámbito sindical-, parte importante de la Jerarquía comenzó a promover, paulatinamente, la militancia católica dentro de los sindicatos potenciados por el peronismo. ${ }^{(105)}$ Esto provocó, luego del triunfo electoral de 1946, el retroceso o el silenciamiento de las figuras enroladas en el antiperonismo.

Ambos, católicos sociales y peronismo, pretendían hegemonizar el movimiento obrero y, para ello, necesitaban cambiar su orientación ideológica, mediante el control del aparato estatal. Con este fin, unos y otros, católicos sociales y grupos próximos a Perón, procuraron arbitrar diversas estrategias: acercamientos y alianzas; tácticas para obtener, acrecentar o preservar el poder; ganar espacio mediante la afinidad o la diferenciación; mecanismos de coerción. Pero, a nuestro juicio, existió una disparidad inicial que marcaría el proceso histórico posterior. Aunque los católicos - sobre todo en Rosario- habían logrado reconstruir sus relaciones con el poder durante los años ' 30 , acrecentando su influencia en el ámbito estatal y acentuando sus tendencias autoritarias, el personalismo de Perón y el pragmatismo que caracterizó su ascenso político, les impidió hacerse con el poder o, al menos, pautó sus vínculos, restándole —o suprimiendo- autonomía en su activi- 
dad sindical. Por tanto, aunque los cuadros dirigentes del catolicismo social rosarino se vincularon al ámbito político de diversas formas, no serían ideólogos ni articuladores privilegiados de la política sindical del gobierno peronista, tal como lo hubieran deseado. ${ }^{(106)}$ Por otro lado, el programa social cristiano no constituía, entonces, una prioridad de la Iglesia institucional y el sector militante del socialcristianismo sólo representaba una minoría que, en adelante, sufriría una fragmentación análoga a la del resto de la sociedad. Ello generaría una relación contradictoria que haría eclosión hacia 1954, cuando las fuerzas adversas al Peronismo reaparecieran con la - en apariencia - sorpresiva fundación de un Partido Demócrata Cristiano.

\section{Notas}

(1) Alcides De Gasperi, El tiempo y los hombres que prepararon la Rerum Novarum, Difusión, Buenos Aires, 1948.

(2) Acla de Fundación del Círculo de Obreros del Rosurio, Rosario, 12 de julio de 1895.

(3) Pbro. Cornelio Vignati, "El Círculo de Obreros y la Acción Social", en: Colocación de la piedra fundamental del edificio propio. $7^{*}$ Congreso Nacional de Círculos de Obreros, Rosario, Octubre de 1922; Gustavo Franceschi, "El deber de sindicarse", en: Criterio, Año XVII, N 856, Buenos Aires, 27 de julio de 1944,

(4) En 1926, la Federación de Círculos de Obreros de la República Argentina contaba con 30.000 afiliados en todo el país. A pesar de no constituir una entidad puramente obrera, la cifra resulta significativa si se considera que, en la misma fecha, la Confederación Obrera Argentina - COA - registraba 86.000 afiliados y la Unión Sindical Argentina -USA-, 10.000. (Crónica del Departamento Nacional del Trabajo, Buenos Aires, Año 1929, N 139).

(5) Los datos estadísticos sobre el COR fueron exuraídos de las siguientes fuentes: Colocación de la piedra fundamental para el edificio propio..., s.p.; La Verdad, Rosario, 10/04/1929; La Verdad, Rosario, 27/03/1930; Cincuentenario de los Circulos de Obrems de la Repriblica Argentina (1892-1942), Talleres Gráficos Victoria, Buenos Aires, 1943.

(6) Esta contradicción se puso de manifiesto en relación con la Sociedad Protectora del Trabajo Libre, que actuaba en los principales puertos del país. Cfr. El Pueblo, 05/10/1905; La Verdad, Rosario, 18/06/1908.

(7) María Pía Martín, "La acción social católica en Rosario (1907-1912)", en: Historia del Sur Santajesino. La sociedad transformada (1850-1930), Ediciones Platino, Rosario, 1993; María Pía Martín, "Católicos, política y sindicatos (1912-1919)", en: Estudios Sociales, Año 2, N² 2, UNL, Santa Fe, primer semestre, 1992.

(8) La Vanguandia, Buenos Aires, 04/10/1905; El Pueblo, Buenos Aires, 05/10/1905.

(9) Agustín Boneo, Obispo de Santa Fe, "Carta Episcopal a las sociedades católicas del Rosario", en: Boletin Eclesiástico de la Diócesis de Santa Fe, Año II, $N^{\circ} 20$, Santa Fe, $1^{\circ}$ de agosto de 1918.

(10) En 1914 se creó un nuevo Círculo de Obreros en la zona de la Refinería Argentina del Azúcar, principal barrio obrero de la ciudad; se fundó la Unión Democrática Cristiana que instaló centros en los barrios de la Refinería, Talleres, Belgrano; y se constituyeron los dos primeros sindicatos católicos de Rosario, uno de Tranviarios y utro de Empleados y Dependientes de Comercio. El primero de ellos llegó a contar con 487 afiliados en 1918, mientras que, en esa fecha, la Federación Obrera Marítima local reunía 450 cotizantes. Maria Pía Martín, "Católicos, política y sindicatos...", op. cit. 
(11) Boletín de la Diócesis de Santa Fe, Santa Fe, 1910-1919; Acción Social, Rosario, 1916-1918.

(12) Cfr. Publicación de la Junta Nacional de la Acción Católica Argentina, La Restauración del onden social. Enciclica Quadragesimo Anno, Buenos Aires, 1931.

(13) La Verdad, Rosario, 26/01/1927; Junta de Gobierno de los Cirrulos de Obreros, VIII Congreso Nacional de los Circulos de Obreros. Anlecedentes, Organización, Aclas, Resoluciones, Estudios Gráficos Velox, Buenos Aires, 1930, págs. 30-31; "La Doctrina de la Acción Católica en Carta Autógrafa de S.S. Pio XI al Episcopado Argentino", en: Anuario Católico Argentino, Publicación de la Junta Nacional de la Acción Católica Argentina, Buenos Aires, págs. 33-50; La Vemlad, Rosario, 1930-1945.

(14) La Verdad, Rosario, 1936-1937; Cfr. Crilerio, Buenos Aires, 1936-1937.

(15) La Convención Constituyente de la Provincia de Santa Fe contó con dos diputados católicos, Francisco Casiello y César A. Berraz, que renunciaron al decidirse la anulación de los artículos referidos a la Iglesia Católica; al Congreso del Trabajo Provincial - 1923- asistieron como delegados del COR. Francisco Casiello, Pedro Beltramino, Roberto Ares y José Sutti; en 1930, el gobierno de facto designó a Francisco Casiello Inspector Jefe de la sede local del Departamento Provincial del Trabajo y a Guillermo Ruiz Díaz como Delegado de la Inspección Nacional del Puerto de Rosario; entre 1938 y 1939, fueron electos Ricardo Herren —diputado provincial-, Francisco Casiello - senador provincial-y Bartolomé Morra - concejal de Rosario-; en 1942, nuevamente Francisco Casiello accedía a una diputación nacional; durante la misma década, su hermano Luis era designado titular del Instituto Psiquiátrico de Oliveros y, luego, Director de Institutos Penales de la Provincia de Santa Fe, y de las Cárceles de Rosario y de Coronda. En general, todos ellos eran egresados de colegios católicos, habían participado de la experiencia demócrata cristiana, en la década de 1910, ocupando distintos puestos directivos dentro de ella y del COR. y, finalmente, se integraron a los cuadros dirigentes de la Acción Católica Argentina, a partir de 1931. Maria Pía Martín, Las prácticas potíticas y sociales del sindicalismo católico argentino. Rosario-Buenos Aires, 1930-1946, mímeo, Rosario, 1996.

(16) Ejemplo claro de ello son las obras de Luis Casiello, El enfermo mental y su asistencia, Librería Editorial "Ruiz", Rosario, 1942; y Cárceles y encarceludos, Librería y Editorial "Ciencia", Rosario, 1949; o las de su hermano, Juan Casiello, Justificación de la Reforma Constitucional. Conferencia pronunciada en el Salón de Actos de la Facultad de Ciencias Económicas, Comerciales y Políticas, el 29 de Octubre de 1948, Rosario, s.e., 1948, e Iglesia y Estado en la Argentina. Régimen de sus relaciones, Editorial Poblet, Buenos Aires, 1948; o la obra de Pedro Beltramino, Tópicos sociales, Imprenta Rodríguez, Rosario, 1942.

(17) En Rosario, durante la primera mitad del siglo, se publicaron los siguientes periódicos católicos: Boletín del Cínculo Católico de Obreros, 1900-1902 y 1919-1920; El Obrero, "Óngano del Círculo de obreros del Rosario", 1902-1906; La Veriad, marzo-diciembre de 1908; La Democracia, enero de 1915-febrero de 1916; El Demócralu, 1916-1919; Acción Social, 1916-1919; La Verilad, 1920-1946; El Heraldo, 1924-1930. Además de publicarse, desde 1900, el Boletín de la Diócesis de Sanla Fe.

(18) Cfr. La Capilah Rosario, 1930-1945; Pedro Beluramino, op. cit.

(19) Entrevista a Elena Osella Muñoz, Rosario, 30 de octubre de 1995.

(20) A fines de la década del ' 30 , la ACA salió a la calle, realizando actos públicos en fechas hasta entonces ignoradas por el mundo católico, como el $1^{2}$ de mayo. La Capilul, Rosario, 02/05/1939; La Verdad, Rosario, 12/05/1939.

(21) Susana Bianchi, La Iglesia Católica y el Estado Peronista, CEAL, Buenos Aires, 1988, págs. 12-13.

(22) Entrevista a Beatriz Casiello, FMA, 7 de diciembre de 1995.

(23) Entrevista a Beatriz Casiello, FMA....; Cfr. Anuario, Junta Nacional de la Acción Católica Argentina, op. cit., pág. 48.

(24) María del Carmen P. Martín, El nacionalismo sindicalista calólico en los onigenes del Peronismo (1928-1930), Rosario, 1991, mímeo.

(25) El Heraldo, Rosario, 1929-1930; La Verdad, Rosario, 1930-1932; Criterio, Buenos Aires, septiembre-diciembre de 1930; La Verdach, Rosario, 25/02/1938.

(26) La Verdad, Rosario, 1930-1932.

(27) Ibídem.

(28) La Verdad, Rosario, 1928-1930. 
(29) "Los estudiantes y la política", en: La Verdad, Rosario, 29/08/1931.

(30) Cristián Buchrucker, Nacionalismo y Peronismo. La Argentina en la crisis ideológica mundial (1927-1955), Sudamericana, Buenos Aires, 1987, pág. 180; La Verdeú, Rosario, julio de 1936.

(31) "España!", en: La Verdach, Rosario, 18/08/1936; "Ante la gran tragedia", en: La Verdad, Rosario, 28/08/1936.

(32) La Verdad, Rosario, octubre-diciembre de 1936.

(33) "El caos español lo dirigia la masonería", en: La Verdad, Rosario, 22/12/1936.

(34) El Heraldo, Rosario, 1924-1930 y el Boletin Eclesiástico de la Diócesis de Sanla Fe, Santa Fe, 1900-1934.

(35) Fernando García Molina y Carlos Mayo, Archivo del General Justo: la Presidencia, CEAL, Buenos Aires, $\mathrm{N}^{2} 192$, pág. 87.

(36) Idem, págs. 89-90.

(37) Idem, pág. 88.

(38) Ibídem.

(39) Idem, pág. 89.

(40) Ibídem.

(41) La Verdad, Rosario, 09/12/1932.

(42) "Expulsión de extranjeros", en: La Verlad, Rosario, 11/03/1932.

(43) Ibídem. Cfr. "Alerta!", en: La Verdad, Rosario, 30/10/1936.

(44) "Deformaciones del concepto libertad", en: La Vertuch, Rosario, 14/06/1935; "Acerca de la labor de depuración en que está empeñado el Gobierno", en: La Verdad, Rosario, 10/09/1943.

(45) "Dos palabras sobre los judíos", en: El Heraldo, Rosario, 14/09/1929.

(46) "Judaísmo", en: La Ventad, 21/09/1934.

(47) Ibídem.

(48) Ibídem.

(49) Maria Pía Martín, Nacionalismo católico, anti-imperialismo y cuestión judia, Rosanio (1920-1930), Rosario, 1993, mímeo.

(50) "Órgano de defensa nacional contra el comunismo", en: La Verdad, Rosario, 11/03/1932.

(51) Ibidem.

(52) Ibídem.

(53) "El problema del comunismo anárquico", en: La Vertad, Rosario, 13/10/1931.

(54) "Acotaciones a una fiesta patria", en: La Verrat, Rosario, 15/07/1935.

(55) "Órgano de defensa nacional contra el comunismo...", op. cit.

(56) "Alerta!", en: La Verrad, Rosario, 30/10/1936.

(57) "El problema del comunismo anárquico...", op. cit.

(58) Ibídem.

(59) Ibídem.

(60) "El problema de la educación y el catolicismo", en: Anuario Católico Angentina, Publicación de la Junta Nacional de la ACA, 1932, Buenos Aires, s.f.

(61) "Un proyecto funesto", en: La Verdad, Rosario, 08/06/1934.

(62) Ibídem.

(63) Ibídem.

(64) "Deformaciones del concepto de libertad", en: La Vertad, Rosario, 14/06/1935.

(65) Alfredo Fragueiro, "Libertad y autoridad", en: El Heraldo, Rosario, 24/11/1928.

(66) "Vehículo de propaganda roja", en: La Verdad, Rosario, 08/05/1942.

(67) Cfr. La Veriad, Rosario, noviembre-diciembre de 1935.

(68) Rodolfo Rivarola, "Sindicalismo", en: La Verdad, Rosario, 15/05/1932.

(69) "Guerra a las asociaciones obreras", en: La Vertad, Rosario, 30/01/1932.

(70) Cfr. Publicación de la Junta Nacional de la ACA, "La Restauración del Orden Social...”, págs. 4445.

(71) "Los frutos del régimen económico liberal y la falta de legislación social", en: La Verdad, Rosario, 28/11/1935.

(72) Ibídem. 
(73) Ibídem.

(74) "El caso Minetti. Nuestras revelaciones han causado viva impresión", en: La Verdad, Rosario, 14/12/1935.

(75) Rodolfo Rivarola, "Sindicalismo", op. cit.

(76) Ibídem.

(77) "Hacia la Depuración de los Partidos Políticos", en: La Vertad, Rosario, 07/07/1943.

(78) La Verdad, Rosario, junio-diciembre de 1943.

(79) Idem.

(80) “Afirmación de la soberania nacional", en: La Verdad, Rosario, 11/08/1944.

(81) "El programa de los sindicatos católicos", en: La Verrad, Rosario, 30/01/1942.

(82) José E. Niklison, "Acción Social Católica", en: Informe del Departamento Nacional del Trabajo, Kosmos, Buenos Aires, 1920, págs. 115-116.

(83) Los católicos consideraban sindicatos paralelos, horizontales o pruros, a los sindicatos de patrones $\mathrm{u}$ obreros organizados separadamente. Arsenio Torres, Manual del sindicalismo obrero católico. Teona y Práctica, Difusión, Buenos Aires, 1943, pág. 25.

(84) "Organización profesional", en: La Verdad, Rosario, 25/02/1944.

(85) "Declaración de Principios de los Círculos de Obreros", en: Junla de Gobiemo de los Círculos de Obreros, VIII Congreso Nacional de los Cúrculos de Obremos. Anteredentes, Organización, Actus y Resoluciones, Buenos Aires, 1930, pág. 53.

(86) Ibídem.

(87) “Organización Profesional", en: La Vertuct, Rosario, 25/02/1944.

(88) Ibídem.

(89) "Deben ser conservados los sindicatos católicos", en: La Verdad, Rosario, 02/02/1945.

(90) Anales de Legislación Argentina, Ediciones La Ley, Buenos Aires, 1945, t. V, pág. 592.

(91) Idem, pág. 593.

(92) En 1938, Monseñor De Andrea calculaba unas 17.500 socias para la Federación de Asociaciones Católicas de Empleadas -FACE-;y en 1942, el sindicato de costureras declaraba 3.000 inscriptosy 1.800 cotizantes. Miguel De Andrea, Calolicismo social. Obras Completas, Difusión, Buenos Aires, 1945, t. IV, pág. 217; La Veriad, Rosario, 30/01/1942.

(93) Lila M. Caimari, Perón y la Iglesia Católica. Religión, Estado y Sociedad en la Angentina (1943-1955), Ariel, Buenos Aires, 1995, págs. 112-115.

(94) Ibídem.

(95) Tal apropiación quedó, muchas veces, en manos de intelectuales puestos a elaborar y difundir doctrina. En el caso de Rosario, resulta interesante el siguiente texto: Juan Bernardo Iturraspe, "El futuro del sindicato en la vida política argentina", conferencia pronunciada en el salón de actos del Ministerio de Agricultura de la Nación, el 28 de agosto de 1947, Comisión de Cultura de "Acción y Doctrina Peronista", Rosario, 1947.

(96) Juan Perón, Justicialismo y la Doctrina Social Cristiana, Presidencia de la Nación, Subsecretaría de Informaciones, 1951.

(97) Fortunato Mallimaci, Catolicismo Inlegral en la Argentina (1930-1946), Biblos, Buenos Aires, 1988, pág. 31.

(98) Juan Carlos Torre, "La C.G.T. y el 17 de Octubre", en: Juan Carlos Torre (comp.), La formación del sindicalismo peronisto, Legasa, Buenos Aires, 1988, pág. 123.

(99) Aunque la presencia de la Iglesia Católica, en Rosario, se había expandido mediante la acción de sus parroquias y escuelas, no sucedía lo mismo con la actividad sindical. Existió, es cierto, una predisposición favorable por parte de la ACA y del COR, que promovieron iniciativas con este fin, pero ellas no lograron plasmarse, efectivamente, en la creación de sindicatos. Cfr. La Venlad, Rosario, 1930-1946; La Capitah, Rosario, 1930-1946.

(100) Juan Carlos Torre, op. cit., págs. 146-147.

(101) Cfr. Astor A. Diehl, "Estado Novo: Corporativismo e Círculos Operários", Separata da Revista Estudos Ibero-Americanos, vol. XIII, $\mathrm{N}^{2} 1$, julio de 1987. 
(102) La crisis de 1954 puso en evidencia que también en educación y familia - temas centrales para la Iglesia-, existia una disputa hegemónica no resuelta, que se hizo explícita ese año por cuestiones coyunturales. Cfr. Susana Bianchi, op. cit.

(103) José Pages, Origen y Desarmllo de la ideas Demorrătico Cristianas en nuestro país. Sus hombres, Escuelas Gráficas del Colegio León XIII, Buenos Aires, págs. 33-34; Juan Belza, S.D.B. Conci, Boceto biográfico de un hombre y unu época, Buenos Aires, s.e., 1964, cap. XIII y XIV.

(104) Juan Belza, S.D.B., op.cit.; Entrevista a Fernando Dalmaso, Rosario, 25 de mayo de 1996.

(105) Cfr. José Pages, op. cit., págs. 33-34; Lila M. Caimari, op. cit., pág. 91.

(106) En este sentido, los catôlicos rosarinos conocían el rol más significativo que desempeñaron la Iglesia y los Círculos de Obreros en el corporativismo brasileño. Cfr. Astor A. Diehl, op. cit.; La Verdud, Rosario, $31 / 08 / 1945$. 